\title{
Immunohistochemical Studies of Cyclic Guanosine Monophosphate and Nuclear Function
}

\author{
Edward M. Rosenberg, James G. Conway, Steven M. Tucci, \\ and Edward W. Doucet, Department of Medicine and Anatomy, \\ Neil Hellman Medical Research Building, Albany Medical College, \\ Albany, New York 12208
}

\begin{abstract}
A B S T RACT In previous immunohistochemical studies, it has been found that all nuclei contain cyclic (c)GMP, which occurs in discrete aggregates and in the nucleolus. We have studied the nature of the cGMP aggregates in isolated mouse fetal nuclei using a specific immunofluorescent technique. These aggregates correspond to the areas of condensation of DNA, demonstrable by either Felugen's or acridine orange stain. Treatment with DNAase eliminated DNA and cGMP staining. Staining for RNA, with a human anti-RNA antibody, demonstrated RNA to be distributed diffusely throughout the nucleus and not preferentially in the areas of discrete cGMP aggregates. The diffuse stain for nuclear RNA was eliminated by pretreatment with RNAase but not DNAase, but aggregates of cGMP were not affected by pretreatment with RNAase. Sites of active RNA synthesis were determined by autoradiography using $\left[{ }^{3} \mathrm{H}\right]$ uridine, and did not correspond to the aggregates of cGMP.

The relationship of cGMP to nucleolar function was examined in the endothelial cells of the isthmus and ampulla of the rat fallopian tube. Previous studies have shown that in proestrous, a period of increased RNA synthesis, nucleoli detectable by staining for RNA appear in the endothelial cells lining the fallopian tube. After immunofluorescent staining, we found prominent accumulation of cGMP in the nucleoli. During other phases of the cycle, there is an absence of nucleoli detectable by staining for RNA, and an absence of nucleolar cGMP. After we treated hypophysectomized or oophorectomized rats with estrogen, which is known to increase nucleolar RNA synthesis in the fallopian tube and endometrium, nucleoli in the endothelial cells of the rat fallopian tube and uterus stained strongly for cGMP.
\end{abstract}

A portion of this study was presented at the 6lst Annual Meeting of the Endocrine Society, Anaheim, Calif., 13-15 June 1979.

Received for publication 21 November 1979 and in revised form 5 June 1980
In conclusion, our studies suggest that the discrete aggregates of nuclear cGMP are associated with a fraction of DNA uninvolved in RNA synthesis. In contrast, cGMP appears in the nucleolus during a period of increased RNA synthesis, suggesting a role for cGMP in regulating nucleolar synthesis and processing of RNA.

\section{INTRODUCTION}

A variety of experimental observations suggest that cyclic GMP (cGMP) could be important in modulating nuclear function. cGMP stimulates phosphorylation of nuclear histone and nonhistone proteins $(1,2)$, and there is evidence that these nuclear phosphoproteins may regulate gene expression $(3,4)$. cGMP also stimulates RNA synthesis in isolated lymphocyte nuclei, and increases the activity of the DNA-dependent RNA polymerase I and III (5). The former is thought to be involved in ribosomal RNA synthesis.

Wedner et al. and others $(6,7)$ have reported on the use of the double antibody immunofluorescent technique for determining the intracellular distribution of cyclic nucleotides. This method employs a specific anticyclic nucleotide antibody, and a fluoresceinated anti-IgG antibody. Spruill et al. (8), using this technique in studies with the polytene chromosomes of Drosophila melanogaster, demonstrated an association of cGMP with sites of active RNA synthesis. It is of interest that in mammalian tissue stained for cGMP, cGMP is found in the perinuclear membrane, in discrete intranuclear aggregates, and in the nucleolus (7). The relationship of the cGMP to nuclear and nucleolar function has not been determined.

In the present study, we have used the immunohisto chemical technique for identifying cGMP to examine the relationship of the discrete aggregates of cGMP to nuclear constituents in isolated mouse fetal nuclei. These studies suggest that the discrete aggregates of nuclear cGMP are closely associated with DNA uninvolved in RNA synthesis. We have also studied the relationship of nucleolar c(GMP to nucleolar function 
in the endothelial cells of the rat fallopian tube and uterus. The nucleolus is the site of ribosomal RNA synthesis and processing. We chose to study the cells of the fallopian tube because previous studies have shown that nucleoli appear in the endothelial cells of the fallopian tube during the proestrous phase of the estrous cycle, presumably reflecting increased nuclear synthesis of ribosomal RNA during proestrous (9). ${ }^{1}$ Using our immunofluorescent methods, we observed a prominent accumulation of CGMP in these nucleoli during the proestrous phase of the estrous cycle. To investigate the possibility that the increase in nucleolar cGMP is secondary to the increased secretion of estrogen in proestrous, we also studied fallopian tubes in hypophysectomized animals after administration of estrogen, and observed formation of prominent nucleoli that stained strongly for cGMP. Previous studies have also shown increased nucleolar size and RNA synthesis in endometrial tissue following estrogen administration to hormonoprivic animals. (10, 11). Using our immunohistochemical technique, we observed a marked increase in nucleolar size of endometrial tissue and a prominent accumulation of cGMP in nucleoli after administration of estrogen to hypophysectomized or oophorectomized rats. Our observation of prominent nucleolar staining for cGMP during periods of increased nucleolar activity suggests that cGMP may have some regulatory function in the nucleolus.

\section{METHODS}

Preparation of mouse fetal nuclei. Crude nuclei were prepared by a modification of the method of Chauveau (12). Female and male albino mice, ICR strain, weighing 25 g were obtained from Camm Research Institute, Inc., Wayne, N. J., and were housed together. Females were checked daily for vaginal semen plugs. Females with evidence of insemination were separated and killed by cervical dislocation on day 10 or 11 of fetal development. Fetal tissue was removed and placed in a solution of sucrose, $0.32 \mathrm{M}$, and magnesium chloride, $3 \mathrm{mM},(3: 1, \mathrm{vol} / \mathrm{wt})$, at $4^{\circ} \mathrm{C}$ and homogenized with three strokes of a Potter Elvehjem tissue grinder. The homogenate was centrifuged at 3,000 rpm (International Equipment Co., Damon Corp., Model PR-6, Needham, Mass.) at $4^{\circ} \mathrm{C}$ for $8 \mathrm{~min}$ and the supernate discarded. The pellet was resuspended in sucrose, $0.128 \mathrm{M}$, and magnesium chloride, $1.2 \mathrm{mM}(3: 1, \mathrm{vol} / \mathrm{wt})$, and incubated at $37^{\circ} \mathrm{C}$ for $10 \mathrm{~min}$. Smears were made of the resultant suspension of nuclei and fixed for $\sim 15 \mathrm{~s}$ in a mixture of methanol and glacial acetic acid $(6: 1$, $\mathrm{vol} / \mathrm{vol}$ ) and air dried.

Rat fallopian tube and uterine nucleoli studies. $150 \mathrm{~g}$ female Sprague-Dawley rats were obtained from Taconic Farms, Inc., Germantown, N. Y. The phase of the estrous cycle was determined by vaginal cytology. During various phases in the estrous cycle, animals were anesthetized with pentobarbital, $160 \mathrm{mg} / \mathrm{kg}$, i.p., and fallopian tissue was removed and rapidly frozen in liquid nitrogen. Tissue was then

\footnotetext{
${ }^{1}$ Doucet, E. W., G. I. Kaye, and F. IV. Harrison. A histochemical study of the rat fallopian tube over the four-day estrous cycle. Anat. Rec. Submitted for publication.
}

placed on a tissue support, and two to four micron sections cut on a "minotome" cryostat 3398, (International Equipment Co.). Hypophysectomized female rats, $150 \mathrm{~g}$, were also obtained from Taconic Farms, and completeness of hypophysectomy was assessed by monitoring of body weights. Only rats manifesting either an absence of weight gain or a progressive weight loss were used. Oophorectomy was performed in normal female rats and the completeness of the oophorectomy monitored by vaginal cytology. A single subcutaneous injection of estradiol, $60 \mu \mathrm{g} / \mathrm{kg}$, in $10 \%$ ethanol in saline, was administered to hypophysectomized or oophorectomized rats, and the animals were killed at various times after the injection. The animals were anesthetized with sodium pentobarbital, $0.1 \mathrm{mg} / \mathrm{g}$, given subcutaneously. Tissue was removed, placed on the tissue support of an International Equipment Co. minotome cryostat 3398, and rapidly frozen on the precooled freezing bar (7). Tissue sections were stained unfixed.

Anti-cGMP antibody. Antibodies were raised in rabbits against succinylated CGMP conjugated to keyhole limpet hemocyanin, by the method of Steiner et al. (13). Antibodies were further purified by isolating the gamma globulin fraction using pluronic polyols F-38 (BASF Wyandotte Chemical Corp., Paramus, N. J.) by a modification of the method of Garcia and Ordonez (14). A description of the affinity characteristics of the cGMP antibody for cGMP, cAMP, and other noncyclic nucleotides has been published separately (16).

Anti-ribonucleic acid antibody. The antibody was obtained by Dr. L. Bartholemew, Albany Medical College, from a patient with mixed connective tissue disease. The antibody produces a speckled pattern on staining of rat hepatic nuclei, as revealed by the immunofluorescent technique, and this was eliminated when the tissue was preincubated with RNAase before staining. The patient's serum contained no detectable antibodies to single or double-stranded DNA.

Immunofluorescent technique. Tissue slices or nuclear preparations were incubated with a rabbit antibody of high affinity for cGMP or with "control serum" from rabbits not injected with cyclic nucleotides. The slices or nuclei were then incubated with a fluorescein-labeled goat anti-rabbit immunoglobulin (Miles Laboratories, Elkhart, Ind.), as described by Wedner et al. (6), with the slight modifications we have described previously (15). Tissue slices or nuclear preparations stained with control antibodies from rabbits not injected with cyclic nucleotides, demonstrated no immunofluorescence. Additional studies supporting the specificity of this technique have been published separately (15).

Autoradiography. 10-d pregnant female mice were injected with $\left[{ }^{3} \mathrm{H}\right]$ uridine, $45 \mathrm{Ci} / \mathrm{mMol}$ i.p. $(2 \mu \mathrm{Ci} / \mathrm{gm})$, and killed $48 \mathrm{~h}$ later. Slides of fetal nuclei were prepared as indicated above. Slides were prepared for autoradiography by the method of Rodgers (16). The slides were dipped in Kodak NTB-3 liquid emulsion (Eastman Kodak Co., Rochester, N. Y.) $\left(45^{\circ} \mathrm{C}\right)$, air dried, and exposed in a light-tight box at $4^{\circ} \mathrm{C}$ for $28 \mathrm{~d}$. They were developed with a Kodak D-19 developer, and a Kodak SB5a stop bath, and counter-stained with Giemsa.

The slides were viewed with a Zeiss photomicroscope III with a vertical illuminator III R.S., a $10-X$ eye piece, 1.25 optivar setting, and a planapochromat 40/1-0 oil lens (1-4617-46) (Carl Zeiss, Inc., New York).

Photography. Photographs were taken with Kodak Technical Pan Film S0115, using an exposure index of 100, and developed with Perfection Micrograin Film Developer (Perfection Photographic Products, Beverly Hills, California) for $20 \mathrm{~min}$ at $82^{\circ} \mathrm{C}$. Prints were made on Illford Illospeed Multigrade Paper MGIM, glossy (Illford Inc., Paramus, N. J.), using a No. 5 or 7 filter (Illford Multigrade Filters) and developed with Illford Illospeed-2 Developer.

Materials. RNAse and DNAse were obtained from Sigma 


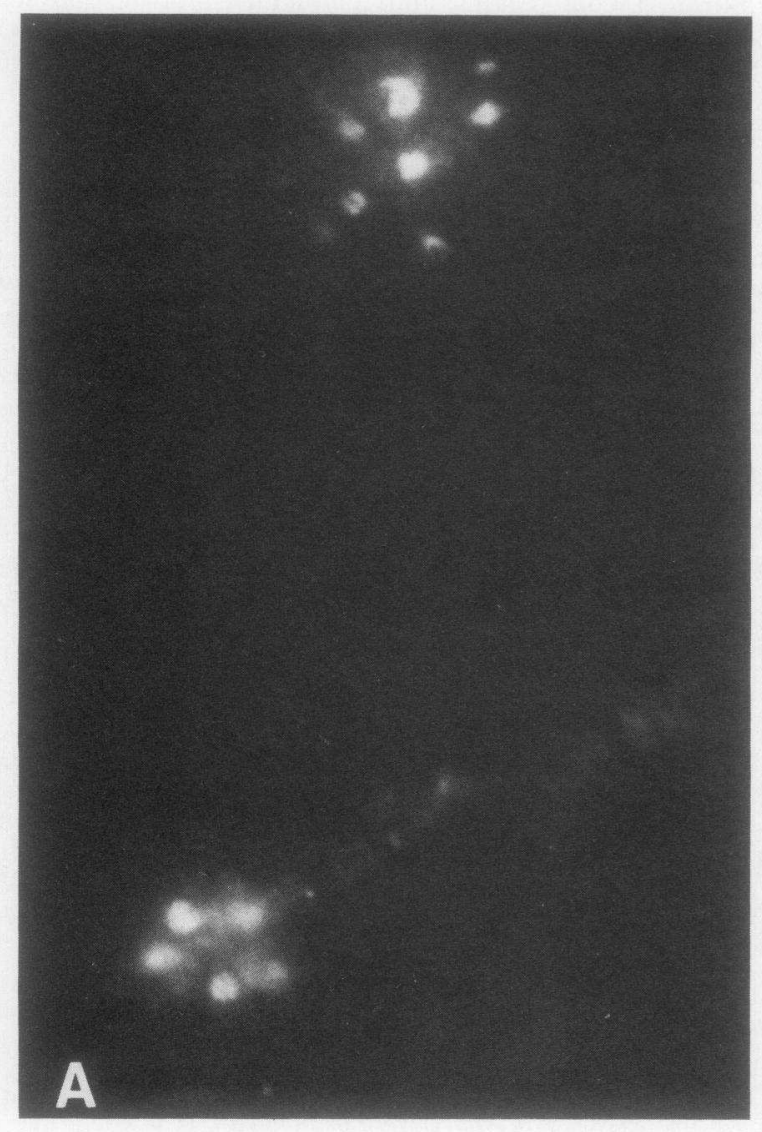

B
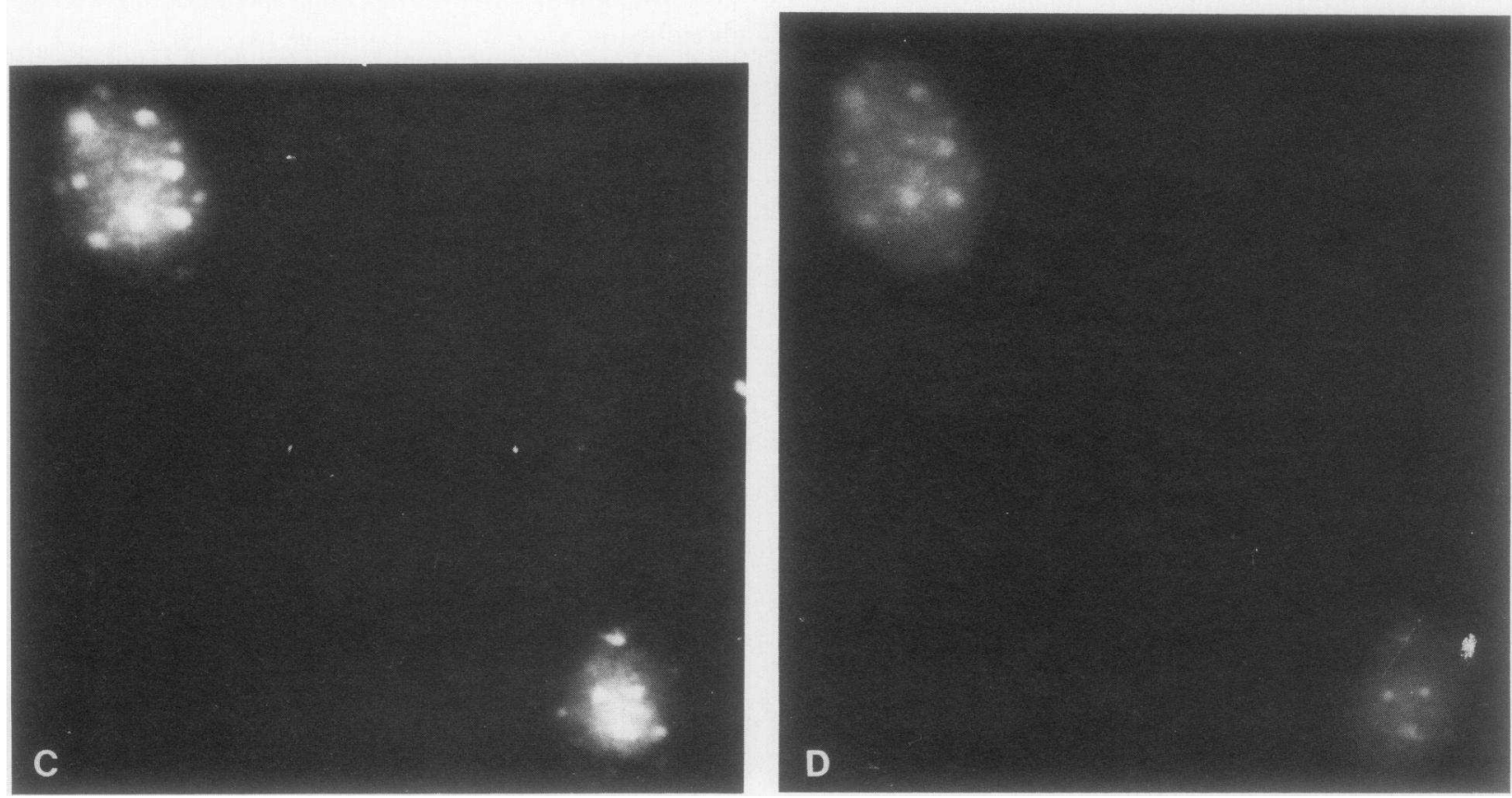

834 E. M. Rosenberg, J. G. Conway, S. M. Tucci, and E. W. Doucet 

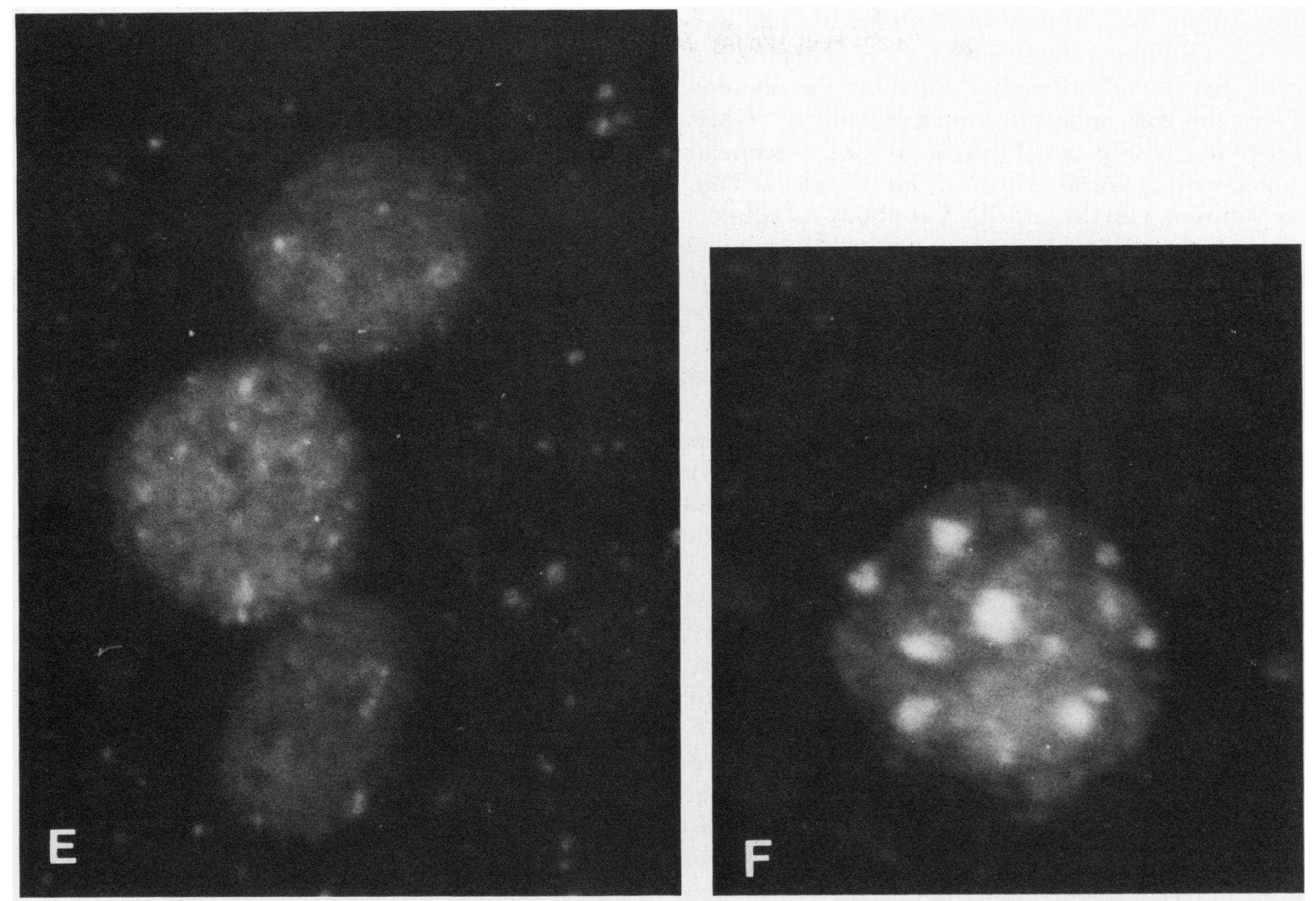

FIGURE 1 Relationship of intranuclear aggregates of cGMP to DNA in mouse fetal nuclei. (A) Nuclei stained for cGMP. (B) Nuclei seen in Fig. 1A, stained for DNA by Feulgen's method. Condensations of DNA correspond to aggregates of cGMP. (C) Nuclei stained for cGMP. (D) Nuclei seen in Fig. 1C, stained for DNA by the acridine orange method. Condensations of DNA correspond to aggregates of cGMP. (E) Nuclei preincubated with DNAase, $1 \mathrm{mg} / \mathrm{cm}^{3}$, for $15 \mathrm{~min}$ at $20^{\circ} \mathrm{C}$, before staining for cGMP. Intranuclear aggregates of cGMP are completely eliminated. $(F)$ Nuclei preincubated with the DNAase buffer only, for $15 \mathrm{~min}$ at $20^{\circ} \mathrm{C}$, prior to staining for cGMP. Intranuclear aggregates of cGMP are unaffected.

Chemical Co., St. Louis, Mo. $\left[{ }^{3} \mathrm{H}\right]$ uridine was obtained from New England Nuclear, Boston, Mass.

\section{RESULTS}

Relationship of cGMP aggregates to nuclear DNA. The relationship of the nuclear aggregates of cGMP to other nuclear constituents was examined in isolated nuclei from mouse fetal tissue. In Figs. $1 \mathrm{~A}$ and 1B, the aggregates of cGMP as demonstrated by our immunohistochemical technique are compared with the distribution of DNA in the same nuclei as determined by Feulgen's stain. In Fig. 1C and Fig. 1D, the aggregates of cGMP are compared with the distribution of DNA in the same nuclei as determined by the acridine orange stain. After photographing of the nuclei stained for cGMP, slides were exposed to UV light for a prolonged period to eliminate immunofluorescence before staining with acridine orange. It can readily be seen that the aggregates of cGMP correspond to condensations of DNA by both methods. Approximately $75 \%$ of mouse fetal nuclei demonstrate the discrete intranuclear cGMP aggregates. Nuclei not demonstrating the discrete aggregates of cGMP do not demonstrate condensations of DNA. In Fig. 1E, smears of nuclei were preincubated with DNAase, $1 \mathrm{mg} / \mathrm{cm}^{3}$, for $15 \mathrm{~min}$ at $20^{\circ} \mathrm{C}$, before staining for cGMP. The intranuclear aggregates of cGMP are completely eliminated. This contrasts with the nuclei in Fig. $1 F$ that were incubated with only the buffer before staining for cGMP, and in which the characteristic intranuclear aggregates are still present. These observations suggest that the aggregated cGMP represents cGMP that is bound to aggregated DNA.

Relationship of cGMP aggregates to nuclear RNA. The relationship of the aggregates of cGMP to nuclear RNA was examined first by using our antiribonucleic acid antibody. Fig. 2B illustrates a nucleus incubated 
with the antibody, and then incubated with a fluoresceinated anti-human IgG antibody. Immunofluorescence is distributed diffusely throughout the nucleus, and does not correspond to the aggregates of cGMP, as illustrated in Fig. 2A. Pretreatment of the smears of nuclei with RNAase, $1 \mathrm{mg} / \mathrm{ml}$, for $15 \mathrm{~min}$ at $20^{\circ} \mathrm{C}$ before staining with the anti-RNA antibody completely eliminated the RNA staining pattern. Pretreatment with DNAase, $0.1 \mathrm{mg} / \mathrm{cm}^{3}$, a concentration that eliminated most of the DNA on Feulgen's stain, had no effect on the pattern of staining produced by the antiRNA antibody. A lower concentration of DNAase was chosen to minimize the effect of contaminating RNAase in the preparation of DNAase. In Fig. 2C, smears of nuclei were pretreated with RNAase, $1 \mathrm{mg} / \mathrm{cm}^{3}$, for $15 \mathrm{~min}$ before staining for cGMP. There was no effect of RNAase on the cGMP aggregates, in contrast to the previously observed effect of pretreatment with DNAase.

In Fig. 3, the relationship of the aggregates of DNA and RNA synthesis was examined by autoradiography. Pregnant mice received tritiated uridine, $2 \mu \mathrm{Ci} / \mathrm{g}$, i.p., and $48 \mathrm{~h}$ later the mice were killed, a preparation of fetal nuclei made, and autoradiography performed. Because we previously observed that the cGMP aggregates correspond to the condensations of DNA, the autoradiographic grains representing newly synthesized RNA were also compared with the DNA condensations seen on Feulgen's stain. Fig. $3 \mathrm{~A}$ is a typical nucleus demonstrating the characteristic grain pattern, and the nucleus is counterstained with Giemsa. Fig. $3 \mathrm{~B}$ is a diagram of the nucleus in Fig. $3 \mathrm{~A}$ outlining the $\left[{ }^{3} \mathrm{H}\right]$ uridine grains. In Fig. 3C, the same nucleus is stained for DNA by Feulgen's technique. Fig. 3D is a diagram of the nucleus in Fig. 3C outlining the areas of presumed condensed DNA. It can be seen that the grains do not correspond to condensation of DNA and, thus, do not correspond to the aggregates of cGMP. It is, therefore, concluded that the aggregates of cGMP probably are not located in areas of RNA synthesis.

The relationship of cGMP to nucleolar function. The relationship of cGMP to nucleolar function was examined in the rat fallopian tube during the estrous cycle and in the fallopian tube and uterus after administration of $17 \mathrm{~B}$ estradiol to hypophysectomized and oophorectomized rats. Fig. 4B illustrates the isthmus of the fallopian tube during the proestrous phase of the estrous cycle stained for cGMP. Of note are the prominent globular intranuclear accumulations of cGMP that have the size and shape of the nucleoli. In studies published separately, ${ }^{1}$ as well as by staining of adjacent tissue slices with acridine orange, these intranuclear structures have been shown to stain positively for RNA, identifying them as nucleoli. Fig. 4A illustrates the isthmus of the fallopian tube during diestrous, and Fig. 4C illustrates the isthmus of the fallopian tube during estrous, both stained for cGMP.
Of note is the absence of detectable nucleoli. Fallopian tissue during the metestrous phase, also lacks detectable nucleoli when stained for cGMP. There is also an absence of detectable nucleoli when fallopian tissue from these three phases of the estrous cycle are stained for RNA with acridine orange. ${ }^{1}$

We examined fallopian tubes from hypophysectomized rats $15 \mathrm{~h}$ after being treatd with estradiol, $60 \mu \mathrm{g} / \mathrm{kg}$, and rats treated with the $10 \%$ ethanol in salient diluent, and using the acridine orange stain for RNA, we found prominent nucleoli only in the tissue from the estrogentreated rats. The nucleoli stained strongly for cGMP (Fig. 5A), whereas there was no corresponding cGMP immunofluorescence in the nuclei of the fallopian tubes from the rats that were not treated with estrogen (Fig. 5B). Fig. 5C illustrates endometrial tissue obtained $15 \mathrm{~h}$ following administration of estradiol to a hypophysectomized rat and stained for cGMP, while Fig. 5D is endometrial tissue from a hypophysectomized rat that received only the diluent. Of note are the prominent nucleoli that stain positively for cGMP and RNA and are seen only in the tissue from the estrogentreated animal. Also of note is the prominent perinuclear cGMP immunofluorescence seen in the tissue from the estrogen-treated animals (Figs. 5A and 5C). Fig. 6A illustrates endometrial tissue obtained $10 \mathrm{~h}$ after administration of estradiol to an oophorectomized rat and stained for cGMP, whereas Fig. 6B illustrates endometrial tissue from an oophorectomized rat that received only the diluent. Prominent nucleoli, which stain positively for cGMP and RNA, are seen only in the endometrial tissue from the estrogen-treated rat. Also of note is the prominent perinuclear cGMP immunofluorescence seen in the tissue from the estrogen-treated animal.

\section{DISCUSSION}

Immunofluorescent techniques for identifying cyclic nucleotides are of great potential value for studying the localization of cyclic nucleotides within cells, and examining changes in their distribution following modification of cell activity. It has been observed previously that cGMP is found in the perinuclear membrane, in the nucleolus, and as discrete intranuclear aggregates, whereas cAMP is found predominantly in the cytoplasm and not in the nucleus (7).

A variety of observations suggest a role for cGMP in the regulation of nuclear and nucleolar function, including the capacity of cGMP to increase the activity of RNA polymerase (5), to stimulate RNA synthesis (5), and to enhance phosphorylation of nuclear proteins (1). Also, the isolation and characterization of a nucleolar cGMP binding protein, and cGMP-dependent protein kinase has recently been reported $(17,18)$. Therefore, we have applied our immunohistochemical 

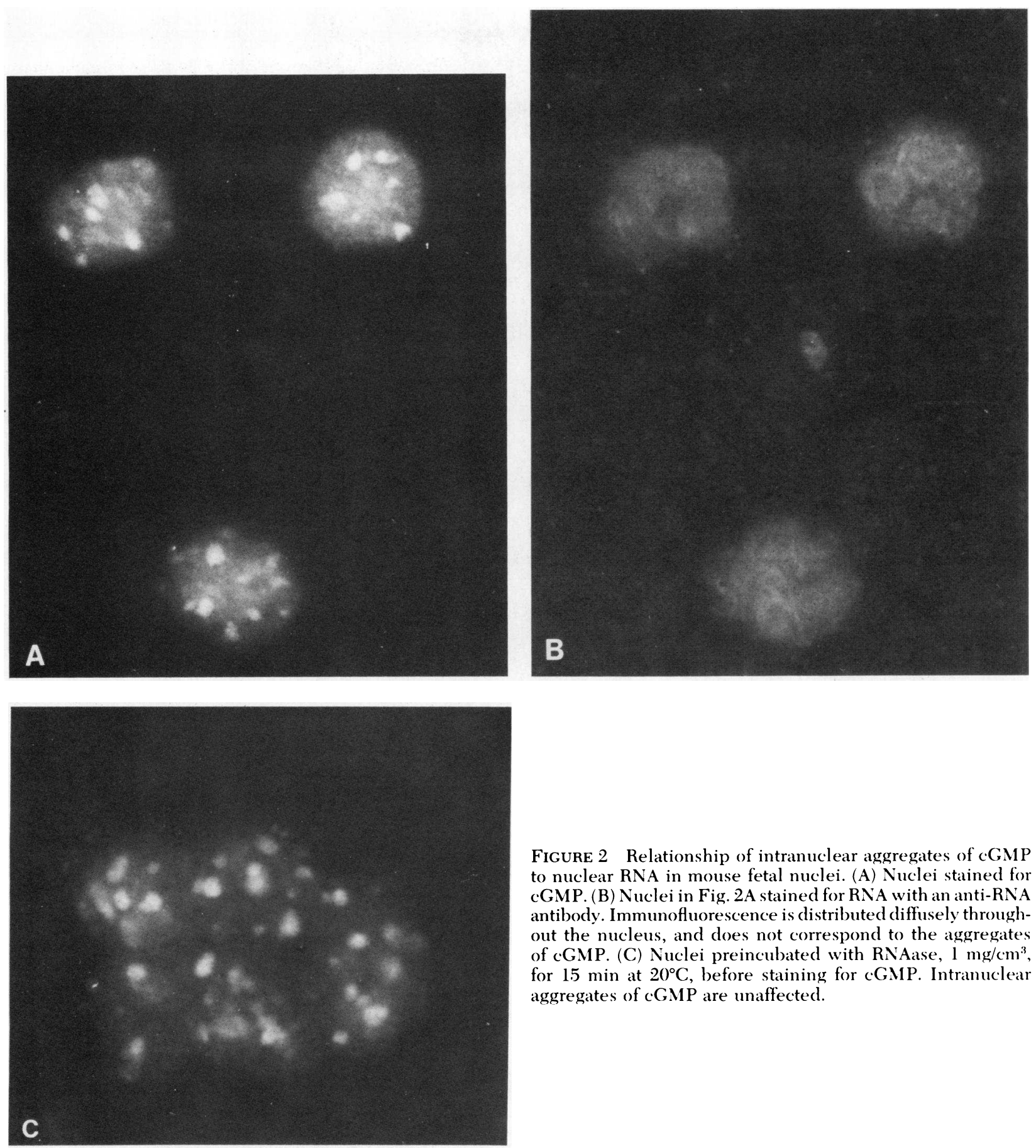

FIGURE 2 Relationship of intranuclear aggregates of cGMP to nuclear RNA in mouse fetal nuclei. (A) Nuclei stained for cGMP. (B) Nuclei in Fig. 2A stained for RNA with an anti-RNA antibody. Immunofluorescence is distributed diffusely throughout the nucleus, and does not correspond to the aggregates of cGMP. (C) Nuclei preincubated with RNAase, $1 \mathrm{mg} / \mathrm{cm}^{3}$, for $15 \mathrm{~min}$ at $20^{\circ} \mathrm{C}$, before staining for cGMP. Intranuclear aggregates of cGMP are unaffected.

techniques to obtain further information relevant to the possible role of cGMP in nuclear and nucleolar function.

We observed that the discrete intranuclear aggregates of cGMP are closely associated with areas of condensed DNA as demonstrated by both Feulgen and acridine orange stains. The association of the cGMP with DNA

was further confirmed by the elimination of the aggregates of cGMP immunofluorescence by pretreatment of the nuclei with DNAase. Because previous studies have suggested that the areas of condensed DNA are not sites of RNA synthesis, we next examined the relationship of the aggregates of cGMP to RNA synthesis to confirm these studies. We began by doing immuno- 

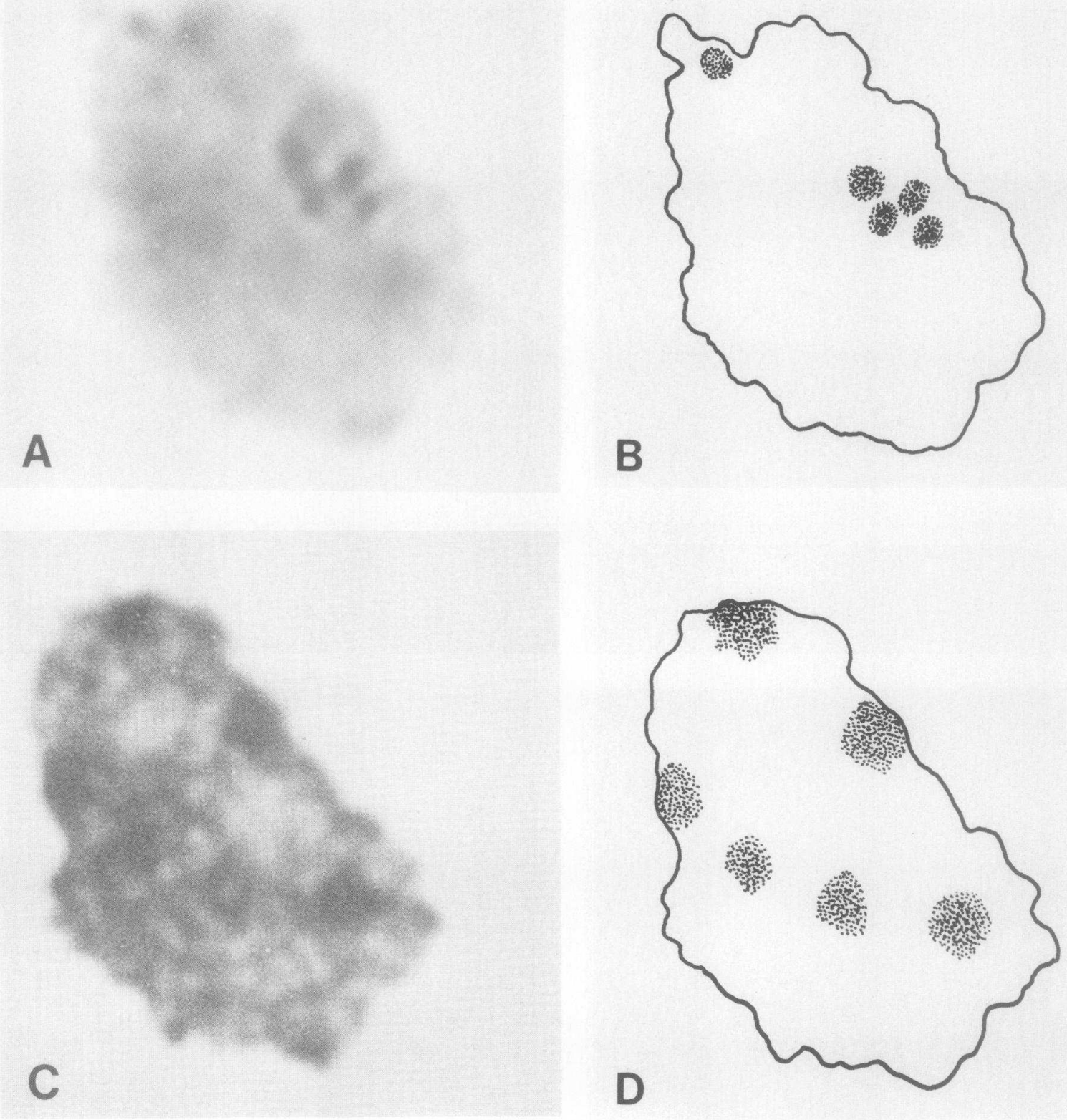

FIGURE 3 Relationship of intranuclear condensations of DNA to RNA synthesis in mouse fetal nuclei. (A) Autoradiograph of nuclei obtained from fetuses from a pregnant mouse injected with $\left[{ }^{3} \mathrm{H}\right]$ uridine, $2 \mu \mathrm{Ci} / \mathrm{g}$ i.p., $48 \mathrm{~h}$ before sacrifice. Nuclei are counterstained with Giemsa. (B) Diagram of the nucleus in Fig. 3A outlining the $\left[{ }^{3} \mathrm{H}\right]$ uridine grains. (C) Nuclei seen in Fig. 3A, stained for DNA by the Feulgen method. (D) Diagram of the nucleus in Fig. 3C outlining the areas of condensed DNA. The grains do not correspond to condensations of DNA and, thus, do not correspond to the aggregates of cGMP.

fluorescent studies for RNA, using a human anti-RNA antibody. The staining pattern for RNA was diffuse in distribution and did not correspond to the aggregates of cGMP. Pretreatment of the slide with RNAase, 1 $\mathrm{mg} / \mathrm{cm}^{3}$, before staining with the anti-RNA antibody, eliminated the diffuse staining pattern, but had no effect on the characteristic intranuclear aggregates of cGMP. The relationship of the aggregates of cGMP 

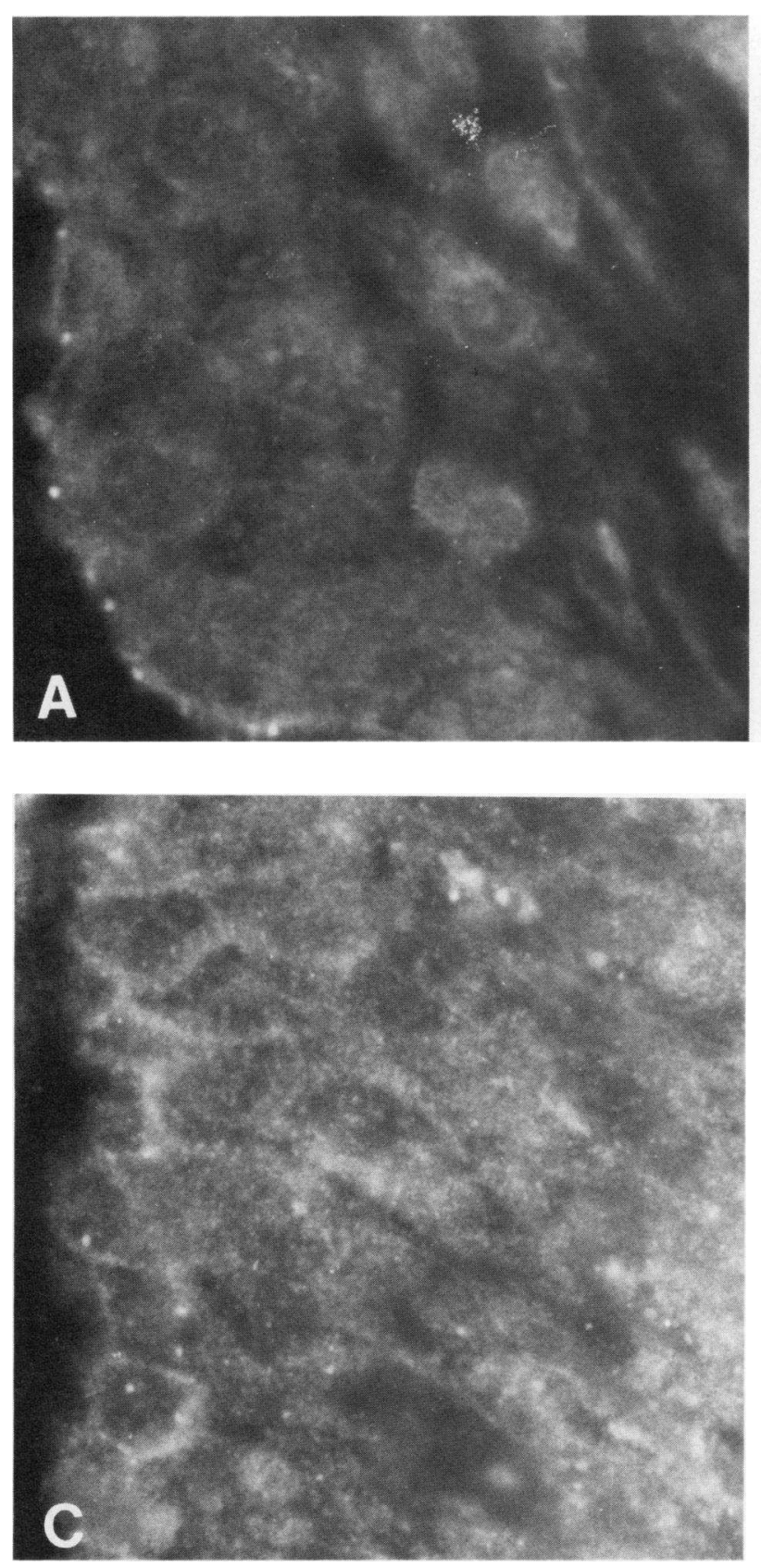

to RNA synthesis was further examined by autoradiography with $\left[{ }^{3} \mathrm{H}\right]$ uridine. A comparison of the distribution of grains seen on autoradiography with the areas of DNA seen on Feulgen stain failed to show any correspondence; this was expected because previous studies have indicated that the areas of condensed DNA are inactive with respect to RNA synthesis (19). Since we have found that the aggregates of cGMP correspond to the areas of condensed DNA, these studies indicate that the aggregates of CGMP are associated with sites of DNA not involved in RNA synthesis.

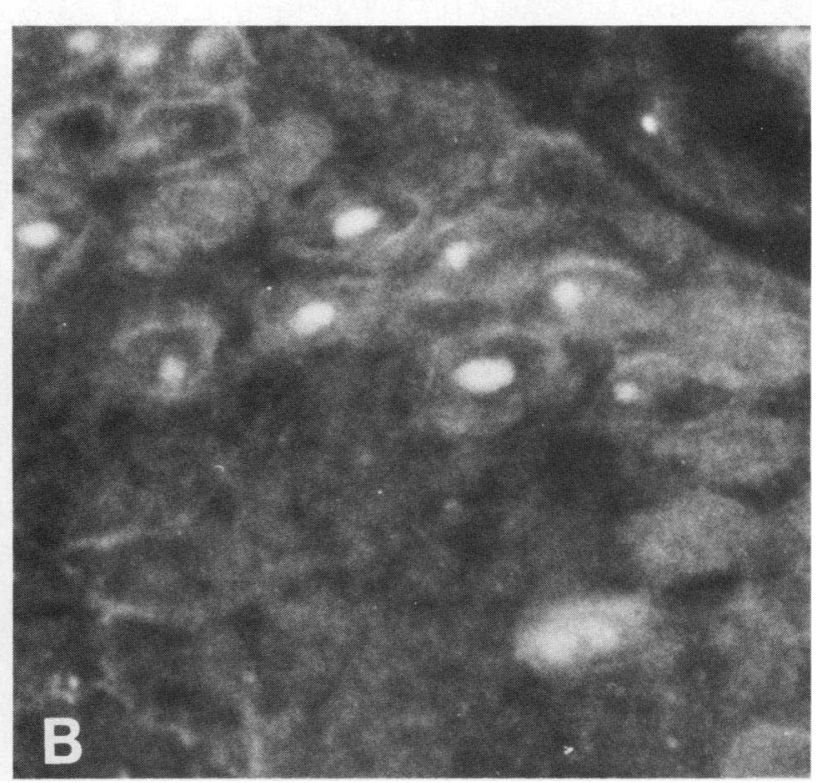

FIGURE 4 Rat fallopian tube stained for cGMP during different phases of the estrous cycle. (A) Diestrous. (B) Proestrous. (C) Estrous. Nucleoli in proestrous tissue stain prominently for cGMP, while nuclei in tissue from diestrous and estrous lack detectable nucleoli when stained for cGMP. 

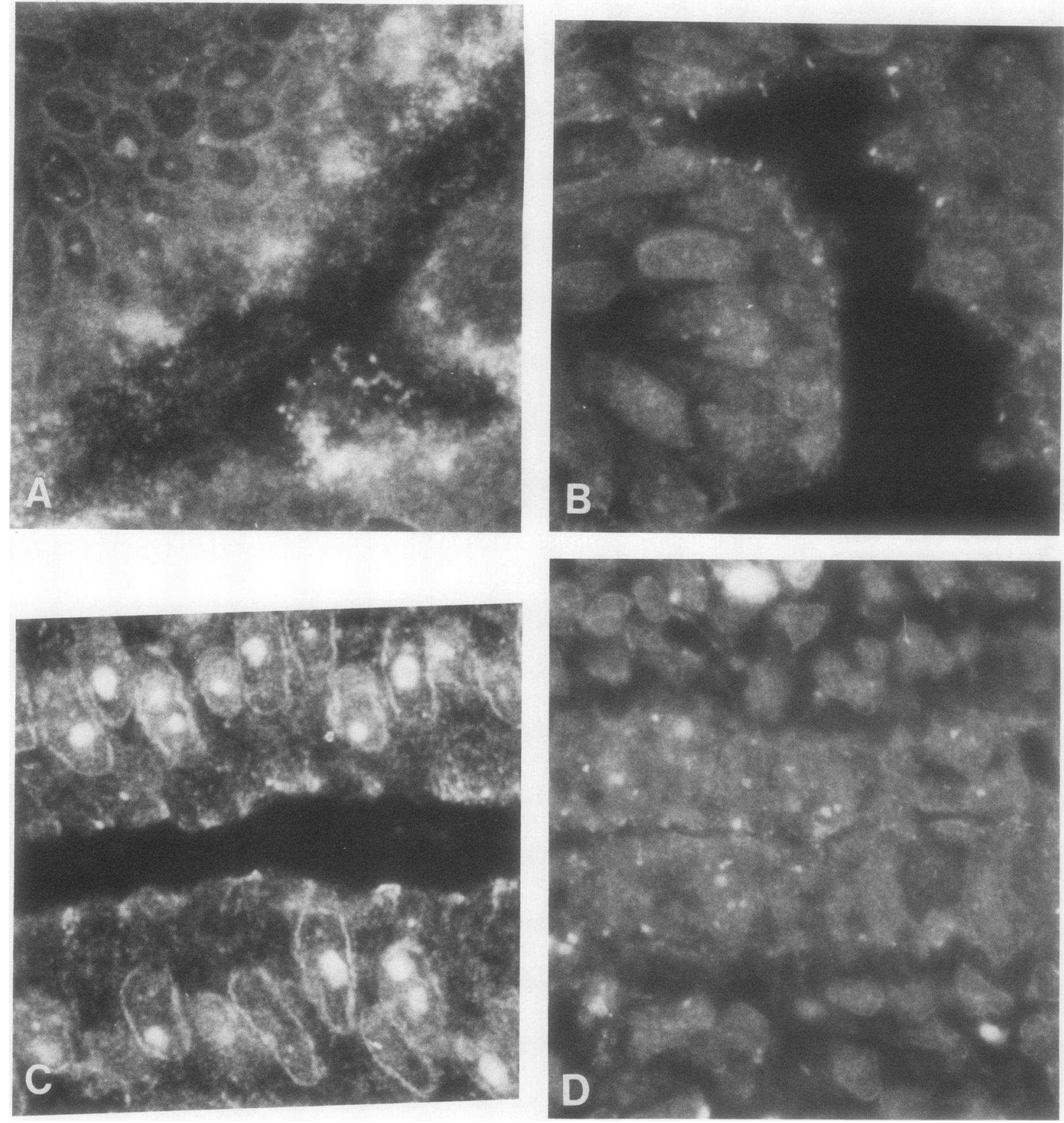

FIGURE 5 Effect of estrogen treatment of the hypophysectomized rat on cGMP immunofluorescence in the fallopian tube and endometrium. (A) Fallopian tube, $15 \mathrm{~h}$ following estradiol administration. (B) Fallopian tube, $15 \mathrm{~h}$ following diluent administration. (C) Endometrium, $15 \mathrm{~h}$ following estradiol administration. (D) Endometrium, $15 \mathrm{~h}$ following diluent administration. Note the appearance of cGMP in the nucleoli and perinuclear membrane in the tissue of the estrogentreated rat, which is not present in the tissue from the rat given diluent alone.

latter observation suggests that the cGMP detected by the immunofluorescent technique is bound to specific cyclic nucleotide receptors.

The other intranuclear site of cGMP staining is the nucleolus, an organelle involved in ribosomal RNA synthesis and processing, suggesting that cGMP may play a role in regulating nucleolar function. Previous studies have shown that prominent nucleoli appear in 

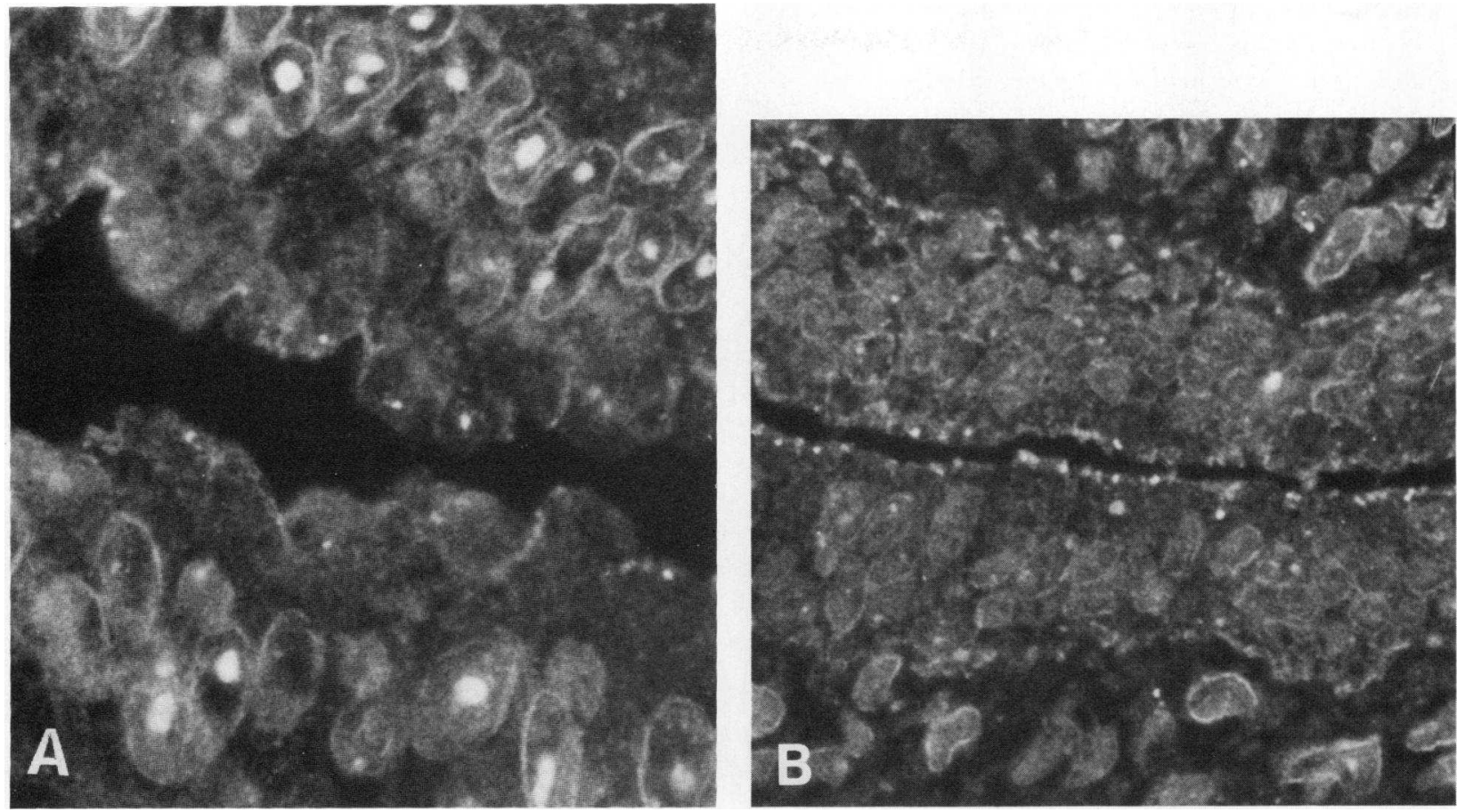

FIGURE 6 Effect of estrogen treatment of the oophorectomized rat on cGMP immunofluorescence in the endometrium. (A) Endometrium, $10 \mathrm{~h}$ following estradiol administration. (B) Endometrium, $10 \mathrm{~h}$ following diluent administration. Note the appearance of cGMP in the nucleoli and perinuclear membrane in the tissue of the estrogen-treated rat, which is not present in the tissue from the rat given diluent alone.

the nuclei of the fallopian tube during the proestrous phase of the estrous cycle, but are absent during other phases of the cycle. ${ }^{1}$ It is relevant that in proestrous there is a marked increase in nucleolar synthesis of ribosomal RNA. Our studies confirm that the nucleolus is definable only during proestrous, and demonstrate prominent nucleolar cGMP staining during this period of presumed increase in nucleolar synthesis of ribosomal RNA. Administration of estrogen to oophorectomized rats has previously been shown to increase nucleolar size and nuclear RNA synthesis in endometrial and fallopian tissue. Following administration of estradiol to hypophysectomized rats, we observed a significant hypertrophy of nucleoli in the endometrial tissue of the uterus, as well as in the endothelial cells of the fallopian tube; and these nucleoli stained prominently for cGMP. A similar prominent increase in nucleolar size and cGMP staining was seen in the endometrial tissue of the uterus following estrogen administration to oophorectomized rats. Thus, both in the fallopian tube in proestrous, and in the endometrium and fallopian tube after estrogen treatment, cGMP appears in the nucleolus during a period of presumed increase in nucleolar synthesis of RNA.

Also of note is the prominent perinuclear cGMP im- munofluorescence which is seen in the tissue from the estrogen-treated animals. Steiner et al. (20) have recently reported an increase in perinuclear cGMP immunofluorescence in hepatic nuclei during hepatic regeneration following partial hepatectomy, also a period of increased RNA synthesis (21).

Following estrogen administration to the oophorectomized rat, there are no changes in the nuclear pattern of cGMP immunofluorescence in endometrial tissue noted at 2 or $3 \mathrm{~h}$. At $24 \mathrm{~h}$, the changes noted at 10 and $15 \mathrm{~h}$ are still present. At $48 \mathrm{~h}$, there is a decrease in nucleolar size, a decrease in the number of nuclei with detectable nucleoli, in part reflecting the decrease in nucleolar size, and a decrease in nucleolar and perinuclear membrane cGMP immunofluorescence. By 60 $\mathrm{h}$, most nuclei demonstrate a pattern of nuclear fluorescence similar to that seen in the diluent-treated animal.

In summary, the findings in this study suggest that the intranuclear aggregates of cGMP are associated with areas of DNA, which are not active in RNA synthesis. Further, since nucleolar synthesis of ribosomal RNA is known to be increased in the fallopian tube in proestrous and in the fallopian tube and endometrium following estrogen treatment, the presence of promi- 
nent cGMP staining of the nucleolus during these periods suggest that the cGMP may play a role in regulating nucleolar synthesis of ribosomal RNA.

\section{ACKNOWLEDGMENTS}

The authors wish to express our thanks to Dr. A. David Goodman for his thoughtful suggestions and critical review of the manuscript, to Dr. Lee Bartholemew for the anti-RNA antibody, to Gary LaVallee for his technical assistance, and to Laura Barton and Christina Schmidt for secretarial assistance.

This study was supported by grant 1R01CA22690 awarded by the National Cancer Institute, Department of Health, Education and Welfare.

\section{REFERENCES}

1. Johnson, E. M. and J. W. Hadden. 1975. Phosphorylation of lymphocyte nuclear acidic proteins: Regulation by cyclic nucleotides. Science (Wash.D.C.). 187: 1198-1200.

2. Langan, T. A. 1964. Phosphorylation of liver histone following the administration of glucagon and insulin. Proc. Natl. Acad. Sci. U. S. A. 64: 1276-1283.

3. Wang, T. U. and N. C. Kostraba. 1975. Stimulation and inhibition of transcription in vivo by non-histone chromosomal proteins. In Chromosomal Proteins and Their Role in the Regulation of Gene Expression. G. S. Stein and L. J. Kleinsmith, editors. Academic Press, Inc., New York. 35-44.

4. Kleinsmith, L. J., J. Stein, and G. Stein. 1975. Direct evidence for a functional relationship between non-histone chromosomal protein phosphorylation and gene transcription. In Chromosomal Proteins and Their Role in the Regulation of Gene Expression. G. S. Stein and L. J. Kleinsmith, editors. Academic Press, Inc., New York. 59-66.

5. Johnson, L. D., and J. W. Hadden. 1975. Cyclic GMP and lymphocyte proliferations: Effects on DNA-dependent RNA polymerase I and II activities. Biochem. Biophys. Res. Commun. 66: 1498-1505.

6. Wedner, J. H., B. J. Haffer, E. Battenberg, A. L. Steiner, C. W. Parker, and F. E. Bloom. 1972. A method for detecting intracellular cyclic adenosine monophosphate by immunofluorescence. J. Histochem. Cytochem. 20: 293294.

7. Steiner, A. L., S. H. Ong, and H. J. Wedner. 1976. Cyclic nucleotide immunocytochemistry. Adv. Cyclic Nucleotide Res. 7: 115-155.

8. Spruill, W. A., D. R. Hurwitz, J. C. Lucchesi, and A. L. Steiner. 1978. Association of cyclic GMP with gene expression of polytene chromosomes of drosophila melanogaster. Proc. Natl. Acad. Sci. U. S. A. 75: 1480-1484.

9. Verhage, H. G., J. H. Abel, Jr., W. J. Tietz, Jr., and M. D. Barrau. 1973. Development and maintenance of the oviduct epithelium during the estrous cycle in the bitch. Biol. Reprod. 9: 460-474.

10. Bush, H., P. Byvoet, and K. Smetana. 1963. The nucleolus of the cancer cell: a review. Cancer Res. 23: 313-339.

11. Gorski, J. 1964. Early estrogen effects on the activity of uterine ribonucleic acid polymerase. J. Biol. Chem. 239: 889-892.

12. Chauveau, J., Y. Moule, and C. Rouiller. 1956. Isolation of pure and unaltered liver nuclei, morphology and biochemical composition. Exp. Cell Res. 11: 317-321.

13. Steiner, A. L., C. W. Parker, and D. M. Kipnis. 1972. Radioimmunoassay for cyclic nucleotides. J. Biol. Chem. 247: 1106-1113.

14. Garcia, L. A., and G. A. Ordonez. 1977. The use of pleuronic polyols in the precipitation of plasma proteins and its application in the preparation of plasma derivatives. Transfusion (Phila.). 16: 32-41.

15. Rosenberg, E. M., G. LaVallee, P. Weber, and S. M. Tucci. 1979. Studies on the specificity of immunocytochemical techniques for cyclic AMP and cyclic GMP.J.Histochem. Cytochem. 27: 913-923.

16. Rogers, A. W. 1973. Techniques of Autoradiography. American Elsevier Publishers, Inc., New York. 2nd edition. 309-312.

17. Kawashima, K., and M. Izawa. 1977. Phosphorylation of a nucleolus specific phosphoprotein in vitro. Biochem. Biophys. Res. Commun. 74: 265-272.

18. Linnala-Kankkunen, A., and P. H. Maenpaa. 1979. A cyclic GMP-dependent histone kinase bound to liver nucleoli. Biochem. Biophys. Acta. 587: 324-332.

19. Bloom, W., and D. W. Fawcett. 1975. Textbook of Histology. W. B. Saunders Company, Philadelphia. 10th edition. 65.

20. Steiner, A. L., Y. Koidi, H. S. Earp, P. J. Bechtel, and J. A. Beavo. Compartmentalization of cyclic nucleotides and cyclic AMP-dependent protein kinases in rat liver: immunocytochemical demonstration. Adv. Cyclic Nucleotide Res. 9: 691-705.

21. Bucher, N. L. R. 1967. Experimental aspects of hepatic regeneration. N. Engl. J. Med. 277: 686-696, 738-746. 